\title{
Estudo radiométrico da Praia da Bacutia em Guarapari-ES
}

\author{
Calheiro, D.S. ${ }^{1}$, Passamai, Jr.J.L. ${ }^{2 *}$ \\ 1 Pós-Graduação em Física de Materiais (FIMAT), UFOP, Ouro Preto, MG, Brasil. \\ 2 Departamento de Física, Universidade Federal do Espírito Santo, Vitória, ES, Brasil.
}

*e-mail: passamaijr@gmail.com

\section{Resumo}

O objetivo do nosso trabalho foi investigar a atividade radioativa na Praia da Bacutia na cidade de Guarapari-ES utilizando uma metodologia dinâmica (variação com tempo). As medidas foram tomadas em tempos distintos durante o período de (março a agosto de 2016). Para tanto um ciclocomputador Etrex-10 foi usado para determinar uma rota na areia da praia usada por banhistas e também um contador Geiger que mediu e armazenou os dados. Foi possível observar que existem alguns fatores como: maré, clima e estação do ano, que causam a variação do nível da radiação na Praia da Bacutia.

\section{Abstract}

The objective of our work was to investigate the radioactive activity in Bacutia Beach in the city of Guarapari-ES using a dynamic methodology (variation with time). Measures were taken at different times during the period from March to August 2016. An Etrex-10 cyclocomputer was used to determine a route in the beach sand used by bathers and also a Geiger counter that measured and stored the data. It was possible to observe that there are some factors such as: tide, climate and season of the year, that cause the variation of the radiation level in Praia da Bacutia.

\section{Introdução}

A publicação de Orlando et al. [1] indicam uma possível relação da atividade radioativa nas praias de Guarapari com efeitos biológicos. Indiferente ao efeito da radiatividade, verifica-se que em geral os autores, anteriores a este estudo, descrevem as propriedades das areias utilizando amostras retiradas em um único local, de forma singular no tempo $[2,3,4]$. Vários trabalhos que relatam a atividade radioativa nas praias de Guarapari que utilizam amostras retiradas em um único local, em uma época específica no tempo.[1]

Neste trabalho foi realizada a medição do nível da atividade radioativa $(\mu \mathrm{Sv} / \mathrm{h})$ presente na praia da Bacutia variando no tempo, os estudos começaram em março de 2016 e foram até agosto de 2016. Nesses seis meses de medidas, o intervalo entre as medidas foi de 7 dias a 15 dias, sendo feita apenas duas medidas por mês.

Para a rota ser seguida várias vezes no mesmo caminho utilizamos as coordenadas de georreferenciamento da tabela a seguir.

Tabela 1: Coordenadas da rota utilizada.

\begin{tabular}{|l|l|}
\hline $20^{\circ} 44^{\prime} 0.68^{\prime \prime} \mathrm{S}$ & $40^{\circ} 31^{\prime} 42.77^{\prime \prime} \mathrm{W}$ \\
\hline $20^{\circ} 43^{\prime} 59.96^{\prime \prime} \mathrm{S}$ & $40^{\circ} 31^{\prime} 44.36^{\prime \prime} \mathrm{W}$ \\
\hline $20^{\circ} 43^{\prime} 59.55^{\prime \prime} \mathrm{S}$ & $40^{\circ} 31^{\prime} 46.02^{\prime \prime} \mathrm{W}$ \\
\hline $20^{\circ} 43^{\prime} 59.55^{\prime \prime} \mathrm{S}$ & $40^{\circ} 31^{\prime} 47.74 " \mathrm{~W}$ \\
\hline $20^{\circ} 43^{\prime} 59.69^{\prime \prime} \mathrm{S}$ & $40^{\circ} 31^{\prime} 49.47^{\prime \prime} \mathrm{W}$ \\
\hline $20^{\circ} 44^{\prime} 0.10^{\prime \prime} \mathrm{S}$ & $40^{\circ} 31^{\prime} 51.14^{\prime \prime} \mathrm{W}$ \\
\hline $20^{\circ} 44^{\prime} 1.00 " \mathrm{~S}$ & $40^{\circ} 31^{\prime} 52.58^{\prime \prime} \mathrm{W}$ \\
\hline $20^{\circ} 44^{\prime} 2.34 " \mathrm{~S}$ & $40^{\circ} 31^{\prime} 53.56^{\prime \prime} \mathrm{W}$ \\
\hline $20^{\circ} 44^{\prime} 3.44 " \mathrm{~S}$ & $40^{\circ} 31^{\prime} 53.77^{\prime \prime} \mathrm{W}$ \\
\hline
\end{tabular}




\section{Resultados e Discussões}

$\mathrm{Na}$ figura 01, registramos as três primeiras medidas realizadas entre o mês de março e abril de 2016 e obtivemos o seguinte gráfico.

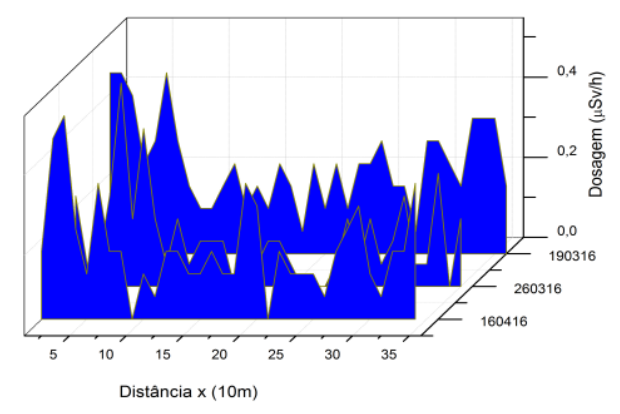

Fig. 01. Gráfico das três primeiras medidas.

Á direita do gráfico acima temos 3 datas que foram feitas as medidas, a primeira foi feita em 19/03/16 a segunda em 26/03/16 e a terceira em 16/04/16.

Observamos nesta praia a medida da radiação não passou de $0,5(\mu \mathrm{Sv} / \mathrm{h})$ ao longo de toda a sua extensão neste período de análise.

Realizamos mais medidas e obtivemos o gráfico a seguir.

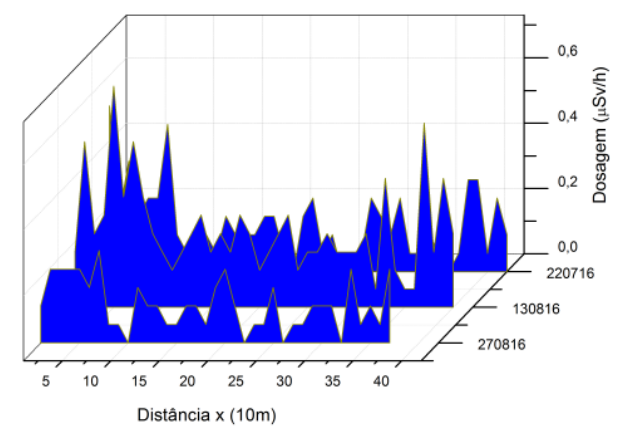

Fig. 02. Gráfico das três últimas medidas.

A medida do dia 13/08/16 mostra a dosagem de $0,676(\mu \mathrm{Sv} / \mathrm{h})$. Esta foi a mais alta medidas registrada neste período.

\section{Conclusões}

Temos neste trabalho a verificação de que a radiação nesta praia varia de intensidade com o tempo, más não temos evidencia de que a radiação se desloca no espaço.

Por ser uma praia que fica entre em região de alta concentração de radioatividade ela foi causou surpresa por estar com níveis que não chegaram em $0,8(\mu \mathrm{Sv} / \mathrm{h})$.

$\mathrm{O}$ ponto a ser ressaltado aqui é de que análises instantâneas de amostras de areia não caracterizam bem a Praia da Bacutia, uma vez que o sistema é dinâmico.

Somente uma análise temporal com base em 1 ano pode fornecer valores médios da atividade radioativa na Praia da Bacutia.

\section{Referências}

[1] Orlando, M T D, et al. Correlation between Breast Cancer and Radiation Level of Guarapari City - ES, Blucher Proceedings ISSN: 2358-2359 V 01, (2014) n 02 DOI:10.5151/phypro-ecfa-020

[2] Fujinami, N.; T. Koga, T.; Morishima. H. External Expousure Rates From Terrestrial Radiantion At Guarapari And Meaipe In Brazil. (1999).

[3] Vasconcelos, D.C, Et Al. Modelling Natural Radioactivity In Sand Beaches Of Guarapari, Espírito Santo State, Brazil. (2013).

[4] Calheiro, D.S.; Passamai. Jr.,J.L. Estudo da Radiação na areia da Praia da Areia Preta. (2016). DOI: 10.5151/phypro-vii-efa-035

Agradecimentos.

Comissão Nacional de Energia Nuclear (CNEN), ao CNPQ e a Fundação de Amparo à Pesquisa e Inovação do Espírito Santo (FAPES) (projetos 098/2019 e 270/2019). 
Blucher Proceedings

$1^{\circ}$ Workshop sobre Areias Monazíticas

Meaípe, Guaraparí- ES, Brasil, May 2019 